\title{
miRNAs in Gastric Cancer
}

\author{
Yu-Lun Liao ${ }^{*}$, Kuo-Wang Tsai ${ }^{*}$ and Wen-chang Lin ${ }^{1}$ \\ ${ }^{1}$ Institute of Biomedical Sciences, Academia Sinica, Taipei; \\ ${ }^{2}$ Department of Medical Education and Research, Kaohsiung \\ Veterans General Hospital, Kaohsiung, \\ Taiwan, Republic of China
}

\section{Introduction}

Gastric cancer (GC) is the most of common cancers, and is especially common in the Andean region of South America and in the Far East (Parkin, Pisani and Ferlay 1999). It can spread throughout the stomach and to other organs, including the esophagus, lungs, lymph nodes or liver. Therefore, gastric cancer is the second leading cause of cancer-related death in the world (Kim et al. 2011). Currently, it remains as one of common cancer types and still be a leading cause of cancer-related death. The development and progression of gastric cancer have been characterized by multiple genetic mutations of proto-oncogenes and tumorsuppressor genes (Wu et al. 2010, Wang et al. 2010).

MicroRNAs (miRNAs) are endogenous non-protein-coding short RNAs of 21-23 nucleotides (Kim, 2005; Bartel, 2004). It was initially discovered in Caenorhabditis elegans and thousands have been identified in many organisms, including human, mammals, invertebrates, insects, plants and viruses. In humans, miRNAs play important roles in cellular physiology, development, and disease by negatively regulating gene expression (Kim, 2005; Bartel, 2004). miRNAs regulate their target genes through targeting 3-UTR region of the gene. While miRNA is imperfect pairing with target gene mRNAs, it may lead to translational repression. Therefore, when perfectly paired with targeting genes, the result was cleavage of the target mRNAs. Depending on their respective target genes, miRNAs could act as tumor-suppressive or in an oncogenesis role. Tumor suppressive miRNAs have usually repressed growth-promoting genes, and oncogenic miRNAs targeted cell growth inhibiting genes.

Previous studies have used an miRNA profiling approach to investigate the function of the miRNA in gastric cancer, showing many miRNAs aberrantly overexpressed or downregulated in gastric cancer progression. Various mechanisms contribute to miRNA aberrant expression during gastric carcinogenesis, including genetic mutation, epigenetic silencing and deregulated transcriptional activity. In this review, we will discuss the detailed mechanisms of miRNA deregulation, such as epigenetic alteration and transcriptional activity in gastric cancer progression. Based on their target genes, we further discuss miRNAs involved in important biological process related to cell growth, cell cycles, apoptosis and cell

${ }^{*}$ Equal contribution 
migration. These miRNA candidates can be used as candidate biomarkers for the detection of gastric cancer and monitoring recurrence.

\section{Alteration of miRNA in gastric cancer}

Since miRNA had been shown as a significant factor during gastric cancer progress, global miRNA expression profiles have been performed using microarray, real-time PCR, or nextgeneration sequencing approaches. The identified dysregulated miRNAs in gastric cancer are listed in Table 1 (Katada et al., 2009a; Guo et al., 2009; Ueda et al., 2010; Ribeiro-dosSantos et al., 2010; Luo et al., 2009; Tsukamoto et al., 2010).

\begin{tabular}{|ccc|ccc|}
\hline \multicolumn{2}{|c|}{ Upregulation in gastric cancer } & \multicolumn{2}{c|}{ Downregulation in gastric cancer } \\
\hline miR-7 & miR-9 & miR-10a & miR-9 & miR-19b & miR-29b/c \\
miR-15a/b & miR-16 & miR-17 & miR-30a/b/c/d/e & miR-31 & miR-128b \\
miR-18a/b & miR-19a/b & miR-20a/b & miR-129 & miR-133b & miR-139 \\
miR-21 & miR-23a & miR-24 & miR-148a/b & miR-152 & miR-155 \\
miR-25 & miR-26b & miR-27a & miR-188 & miR-195 & miR-197 \\
miR-30a & miR-34a/b/c & miR-92 & miR-218 & miR-338 & miR-370 \\
miR-93 & miR-103 & miR-106a/b & miR-375 & miR-378 & miR-383 \\
miR-107 & miR-128 & miR-128 & miR-422b & miR-433 & miR-451 \\
miR-135a/b & miR-146a & miR-181a/b/c/d & miR-490 & miR-497 & miR-503 \\
miR-191 & miR-192 & miR-194 & miR-545 & miR-55la & miR567 \\
miR-200b & miR-212 & miR-215 & miR-575 & miR-611 & miR-630 \\
miR-222 & miR-223 & miR-224 & miR-638 & miR-649 & miR-652 \\
miR-320 & miR-345 & miR-379 & miR768 & & \\
miR-409 & miR-425 & miR-429 & & & \\
miR-518b & & & & & \\
\hline
\end{tabular}

Table 1. Summary of the dysregulation of miRNAs in gastric cancer

However, the factors causing miRNA dysregulation are very complex. The process is composed of multiple steps, including (1) pri-miRNA transcriptional regulation; (2) miRNA maturation process; (3) genetic alteration. The miRNAs serve as tumor suppressors or oncogenes depending on their target genes. Therefore, we have reviewed previous studies which have elucidated the mechanism of dysregulated miRNAs and their confirmed targets during gastric cancer progress, and we have listed these important studies in Table 2.

\section{Mechanism of miRNA deregulation in gastric cancer}

There is a lot of information on aberrantly expressed miRNAs and their tumorigenic effect in gastric cancers, but the clear mechanisms of such miRNA deregulation remain poorly understood. Recent studies have identified some possible mechanisms including epigenetic alteration and deregulated transcription. 


\subsection{Epigenetic regulation of miRNAs expression in gastric cancer}

Epigenetic regulation includes histone modification and DNA methylation, processes which are involved in regulation of cell growth and development in mammals. DNA methylation

\begin{tabular}{|c|c|c|c|c|}
\hline \multicolumn{5}{|c|}{ Tumor suppressive microRNAs } \\
\hline microRNA & Regulator & Function & Target genes & References \\
\hline Let-7 family & & cell migration & RAS , HMGA2,RAB $40 \mathrm{C}$ & $\begin{array}{l}\text { (Motoyama, Inoue et al. 2008; Ohshima, Inoue et al. } 2010 \text {; } \\
\text { Yang, Jie et al. 2011) }\end{array}$ \\
\hline miR-9 & hypermethylation & cell growth, cell cycle & NF-kB1; CDX2: RAB34 & $\begin{array}{l}\text { (Luo, Zhang et al. 2009; Wan, Guo et al. 2010; Rotkrua, } \\
\text { Akiyama et al. 2011) }\end{array}$ \\
\hline miR-29 & & cell growth, cell migration & $\mathrm{Cde} 42$ & (Lang, Liu et al. 2010) \\
\hline miR-34 & hypermethylation & $\begin{array}{l}\text { cell growth, cell cycle, } \\
\text { apoptosis }\end{array}$ & Bcl-2, Notch, HMGA2 & $\begin{array}{l}\text { (Ji, Hao et al. 2008; Suzuki, Yamamoto et al. 2010; Tsai, Wu et } \\
\text { al. 2011) }\end{array}$ \\
\hline miR-101 & & cell growth, cell migration & EZH2, Cox-2, Mcl-1 and Fos & (Varambally, Cao et al. 2008; Wang, Ruan et al. 2010) \\
\hline miR-107 & & cell growth, cell cycle & CDK6,DRCE1 & (Li, Zhang et al. 2010, Feng, Xie et al. 2011) \\
\hline miR-126 & & cell growth, cell migration & SOX2;Crk & (Feng, Chen et al. 2010; Otsubo, Akiyama et al. 2011) \\
\hline miR-125a & & cell growth & ERBB2 & (Nishida, Mimori et al. 2011) \\
\hline $\operatorname{miR}-129$ & hypermethylation & cell growth & SOX $4 ;$ Cdk6 & $\begin{array}{l}\text { (Shen, Pan et al. 2010; Wu, Qian et al. 2010; Tsai. Wu et al. } \\
\text { 2011) }\end{array}$ \\
\hline $\operatorname{miR}-137$ & hypermethylation & cell cycle, apoptosis & $\mathrm{Cdc} 42$ & (Chen, Chen et al. 2011) \\
\hline miR-141 & & cell growth & FGFR2 & (Du, Xu et al. 2009) \\
\hline miR-148 & & cell growth & CCKBR & (Song, Yue et al. 2011) \\
\hline miR-181c & hypermethylation & cell growth & NOTCH4, KRAS & (Hashimoto, Akiyama et al. 2010) \\
\hline miR-200 family & BARF0,EBNAI,LMP2A & cell growth & & (Shinozaki, Sakatani et al. 2010) \\
\hline miR-212 & hypermethylation & cell growth & myc, MeCP2 & (Wada, Akiyama et al. 2010; Xu, Wang et al. 2010) \\
\hline miR-218 & & cell migration & Robol, NFkB & (Gao, Thang et al. 2010; Tie, Pan et al 2010) \\
\hline miR-331 & & cell growth & $\mathrm{E} 2 \mathrm{~F} 1$ & (Guo, Guo et al, 2010) \\
\hline $\operatorname{miR}-375$ & & cell growth & JAK2; PDK1, 14-3-3zeta & (Ding, Xu et al. 2010; Tsukamoto, Nakada et al. 2010) \\
\hline miR-433 & & & GRB2 & (Luo, 7hang et al. 2009) \\
\hline miR-512 & hypermethylation & cell growth, apoptosis & PTEN,Mcl-1 & (Saito, Suzuki et al. 2009) \\
\hline miR-516a & hypermethylation & cell migration & sulfatase 1 & (Takei, Takigahira et al. 2011) \\
\hline \multicolumn{5}{|c|}{ Oncogenesis microRNA } \\
\hline miR-16 & $\mathrm{NF}-\mathrm{kB}$ & cell growth & $\mathrm{Bcl} 2$ & (Xia, Zhang et al. 2008; Shin, Jin et al. 2011) \\
\hline miR-21 & $\mathrm{NF}-\mathrm{kB}$ & cell growth & PDCG4, & (Motoyama, Inoue et al. 2010; Shin, Jin et al. 2011) \\
\hline $\operatorname{miR}-27 \mathrm{a}$ & & cell growth & prohibitin & (Liu, Tang et al. 2009) \\
\hline $\operatorname{miR}-43 \mathrm{c}$ & & cell cycle & VEZT & (Guo, Jing et al. 2011) \\
\hline miR-106b/93/25 & E2F1 & cell growth, cell cycle & $\mathrm{p} 57, \mathrm{p} 21$ & (Petrocca, Visone et al. 2008; Kim, Yu et al. 2009) \\
\hline miR-130b & & cell growth & RUNX3 & (Lai, Koh et al. 2010) \\
\hline $\operatorname{miR}-150$ & & cell growth, apoptosis & EGR2 & (Wu, Jin et al. 2010$)$ \\
\hline miR-1 $81 \mathrm{~b}$ & & apoptosis & $\mathrm{Bcl} 2$ & (Zhu, Shan et al. 2010) \\
\hline miR-192 & & cell growth; cell migration & ALCAM & (Jin, Selaru et al. 2010) \\
\hline miR-199a & & cell growth, cell migration & MAP3K 11 & (Song, Zeng et al 2010 ) \\
\hline $\mathrm{miR}-221 / 222$ & & cell growth, cell cycle & $\mathrm{p} 27, \mathrm{p} 57$ & (Kim, Yu et al. 2009; Chun-Zhi, Lei et al. 2010) \\
\hline $\operatorname{miR}-372$ & & $\begin{array}{l}\text { cell growth, cell cycle, } \\
\text { apoptosis }\end{array}$ & LAS2 & (Cho, Shin et al. 2009) \\
\hline $\operatorname{miR}-421$ & & cell growth & CBX7,RBMXL1 & (Jiang, Guo et al. 2010) \\
\hline miR-497 & & apoptosis & $\mathrm{BCL} 2$ & (Zhu, Zhu et al. 2011) \\
\hline $\operatorname{miR}-650$ & & cell growth, cell migration & ING4 & (Zhang, Zhu et al. 2010) \\
\hline
\end{tabular}

Table 2. Studies confirming aberrant miRNAs expressed in gastric carcinoma

plays an important role in regulation of gene expression through establishing and maintaining the DNA methylation status of gene promoters. Previous studies have demonstrated that abnormal methylation patterns lead to gastric carcinogenesis through the hypermethylated promoter of tumor suppressor genes (Watanabe \& Maekawa, 2010). The basic transcription mechanism of miRNA is fundamentally similar to that of classic proteincoding genes, hence, the hypermethylated promoter region of tumor-suppressive miRNAs may result in gastric cancer formation and progression. Recently, we identified the 48 methylation-regulated miRNAs in AGS cells using a real-time PCR microRNA expression profile (Tsai et al., 2009). In this profile, our laboratory first identified a primate-specific 
miRNA cluster (C19MC) comprising 46 pre-miRNAs, C19MC, which could be co-regulated in placenta tissue by methylating its distal CpG-rich domain (Tsai et al., 2009; Noguer-Dance et al., 2010). A recent study showed that C19MC displays a maternal-specific methylation imprint acquired in oocytes (Noguer-Dance et al., 2010). Saito et al. reported that epigenetic activation of miR-512-5p induces suppression of Mcl-1, resulting in apoptosis of gastric cancer cells (Saito et al., 2009). Accumulating evidence indicates that several tumor-suppressive miRNAs have been shown to contain the aberrant hypermethylation of their promoter regions in human cancers, including miR-9, miR-34b/c, miR-129, miR-137, miR-181C, miR199a, miR-212, miR-512 and miR-516 (Cheung et al., 2011; Luo et al., 2009; Saito et al., 2009; Shen et al., 2010; Suzuki et al., 2010; Tsai et al., 2009; Tsai et al., 2011; Xu et al., 2010) (Figure 1).

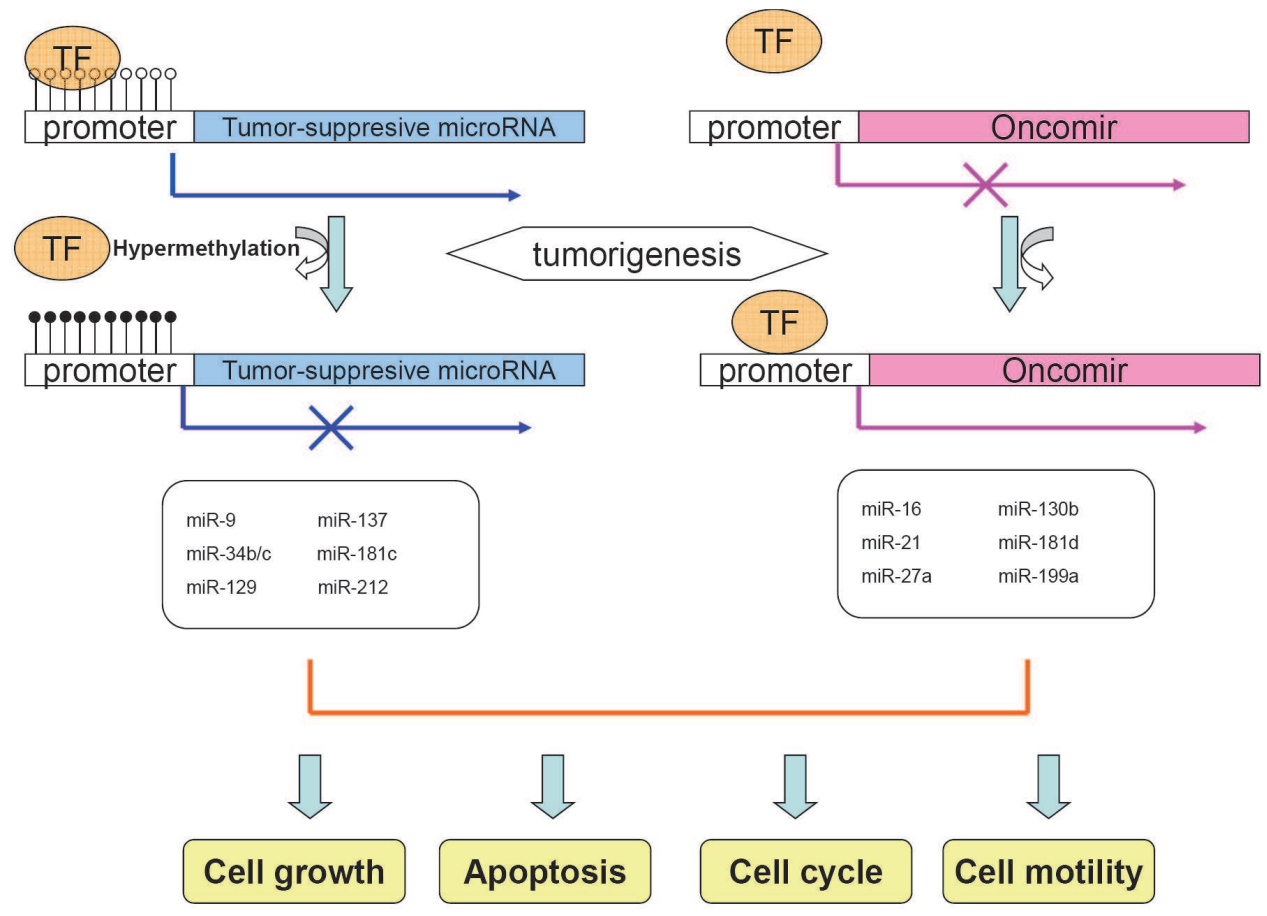

Fig. 1. Schematic diagram depicting miRNA dysregulation and its function in gastric carcinogenesis.

Hypermethylation silencing miR-129 expression is associated with a poor clinical outcome in gastric cancer, and restoration of miR-129 downregulated SOX4 and Cdk6 expression. Overexpression of miR-129-2 could inhibit cell growth and induce apoptosis through suppression of its target genes in gastric cancer cells (Shen et al., 2010; Tsai et al., 2011; Wu et al., 2010a). Hypermethylation leads miR-9 underexpression and affects cell growth and the cell cycle through regulating NF-кB1, CDX2, RAB34 (Luo et al., 2009; Rotkrua et al., 2011; Wan et al., 2010). Transfection of an anti-miR-9 molecule significantly inhibited cell growth 
by promoting G1 cell cycle arrest in MKN45 cells similarly to the effect of CDX2 (Rotkrua et al., 2011).

Tumor-specific transcriptional repression via promoter hypermethylation is often associated with the silencing of tumor suppressive miRNA. Interestingly, a DNA-methylationdependent transcriptional regulation of oncomir, miR-196b, was dramatically overexpressed in gastric cancer tissue samples with a hypomethylated promoter (Tsai et al., 2010). Therefore, DNA methylation plays a critical role in gastric cancer, and involved in the control of the imprinting genes during developmental stages, or tumor-suppressive miRNAs / oncomirs in gastric tumor development (Figure 2).

\footnotetext{
(I) tissue- and development-specific
gene expression, silencing of the
imprinting gene.
}

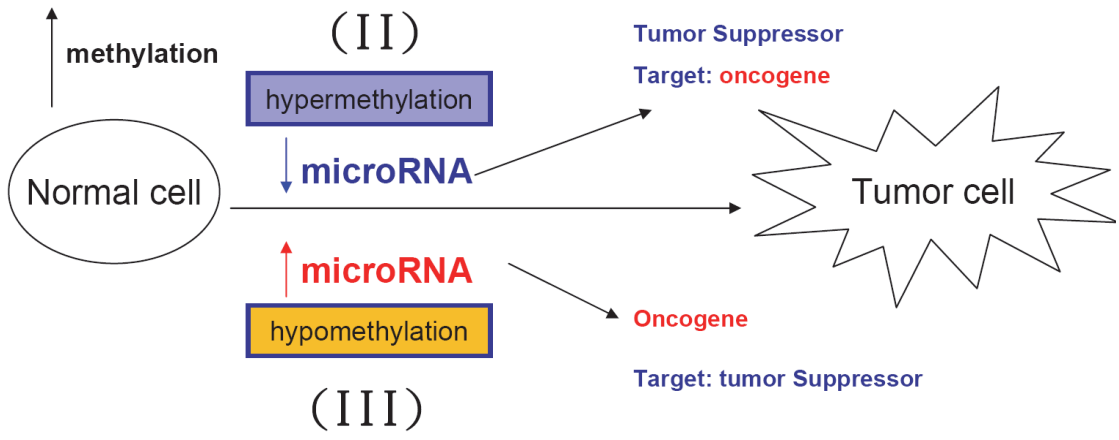

Fig. 2. Schematic diagram depicting miRNA regulation by DNA methylation in gastric carcinogenesis.

\subsection{Deregulated transcription of miRNAs in gastric cancer}

Like the classic protein-coding genes, the possibility of up- or downregulation of miRNAs could also be controlled by transcription factors. E2F1 transcription factor could directly upregulate the transcription of miR-106b-25 cluster in gastric cancer cells. Conversely, miR106b and miR-93 regulate E2F1 expression, establishing a miRNA-directed negative feedback loop (Petrocca et al., 2008). Shin et al. found that miR-16 and miR-21 are directly regulated by the transcription factor NF- $\mathrm{KB}$ in nicotine-treated gastric cancer cells (Shin et al., 2011). miR-34 was thereby demonstrated to be involved in the network and tumor suppressing pathways of p53 as a downstream target of p53 (Ji et al., 2008). Alteration of genes involved in miRNA processing could also contribute to miRNA deregulation. Recent studies reported that both Ago2 and TNRC6A are related to the execution of the genesilencing function of miRNA, and are observed in gastric cancer with high microsatellite instability (Kim et al., 2010). It has been reported the expression of Dicer1 and Drosha are different in non-neoplastic and neoplastic gastric tissues (Tchernitsa et al., 2010).

\section{Putative role of miRNAs in gastric cancer}


Previous studies revealed a broad variety of oncogenes and tumor suppressor genes regulated by different miRNAs in gastric cancer cells. Recent research has revealed evidence showing that miRNAs play roles in the initiation and progression of cancer (Volinia et al., 2006). Some of these miRNAs modulate expression of known oncogenes or tumor suppressor genes, whereas others function as so-called onco-miRs or tumor-suppressormiRs. Furthermore, evidence for regulation of carcinogenesis by miRNAs has been obtained, including promotion of proliferation, migration, invasion and anti-apoptosis.

\section{1 miRNAs and the cell cycle}

Increased cell proliferation is a common feature of gastric carcinogenesis. The miR-222-221 and miR-106b-25 clusters have been found abnormally upregulated in gastric cancer tissues and reported to suppress the p21 family of CDK inhibitors (p57Kip2, p21Cip1, and p27Kip1) (Kim et al., 2009). Ectopic expression of miR-222-221 and miR-106b-25 clusters result in activation of CDK2 activity and facilitates the G1/S phase transition. Inhibition of miR-372suppressed proliferation, arrested the cell cycle at G2/M phase, and increased apoptosis through downregulation of a tumor suppressor gene, LATS2 in gastric cancer cells (Cho et al., 2009). Deregulation of E2F1 activity is characteristic of gastric tumorigenesis and Guo et al. found that overexpression of miR-331-3p blocked G1/S transition in gastric cancer cell lines. miR-331-3p functions in cell cycle control by targeting cell cycle-related molecule E2F1 (Guo et al., 2010). A previous study provided evidence that downregulation of miR-663 in tumor cells may contribute to aberrant cell hyperplasia by indirectly affected upregulation of cyclin B, leading to the development of gastric cancer. Therefore, miR-663 might function as a potent suppressor of tumor growth (Pan et al., 2010). miR-126 was significantly downregulated in gastric cancer tissues. Ectopic expression of miR-126 potently inhibited cell growth by inducing cell cycle arrest in G0/G1 phase in gastric cancer cells. miR-126 may function as a tumor suppressor, and was capable of regulating Crk in gastric cancer (Feng et al., 2010). Restoration of the miR-137 expression downregulated the Cdc42 expression and induced cell cycle G1 arrest in gastric cancer cells. The miR-137 expression was found to be inversely correlated with CDC42 expression in gastric cancer. miR-137 is downregulated in gastric cancer and is a indirectly negative regulator of Cdc42 (Chen et al., 2011). Cyclindependent kinase 6 (CDK6) is found to be upregulated in gastric cancer and has been implicated in tumor initiation and progression. Feng et al. have identified miR-107 as a potential regulator of CDK6 expression. Ectopic expression of miR-107 reduced both mRNA and protein expression levels of CDK6, inhibited proliferation, induced G1 cell cycle arrest. miR-107 may have a tumor suppressor function by directly targeting CDK6 to inhibit the proliferation in gastric cancer cells (Feng et al., 2011). Otsubo et al. demonstrated that SRY (sex determining region Y)-box 2 (SOX2) plays important roles in growth inhibition through cell cycle arrest and apoptosis, and that SOX2 expression is frequently downregulated in gastric cancers. They found miR-126 targets SOX2 in gastric cancer cells. Aberrant overexpression of miR-126 and consequent SOX2 downregulation may contribute to gastric carcinogenesis (Otsubo et al., 2011). These findings suggest that aberrant miRNA expression may enhance cell-cycle progression through direct or indirect regulation of cell-cycle regulators.

\section{2 miRNAs and apoptosis}


Escape from the process of apoptosis is a hallmark of cellular transformation. miRNA dysregulation has been shown to regulate apoptosis by altering the expression of $\mathrm{Bcl}-2$ family members in gastric cancer. Disturbances in apoptotic pathways lead to uncontrolled cell proliferation which indicates a critical step in tumor development.

Forced expression of miR-21 significantly promoted cell proliferation and inhibited apoptosis in gastric cancer cells. Zhang et al. have identified RECK as the direct target of miR-21. RECK is a tumor-suppressor gene in gastric cancer and the oncogenic effect of miR21 may be mediated by regulation of RECK (Zhang et al., 2008). miR-218 expression was reduced significantly in gastric cancer tissues and overexpression of miR-218 inhibited cell proliferation and induced apoptosis in gastric cancer cells through direct targeting of Epidermal growth factor receptor-coamplified and overexpressed protein (ECOP), a positive regulator of NF- $\kappa B$ transcriptional activity. Overexpression of miR-218 also inhibited NF- $\kappa B$ transcriptional activation and transcription of cyclooxygenase-2, a proliferative and antiapoptotic gene regulated by NF- $\kappa B$ (Gao et al., 2010). Overexpression of miR-150 in gastric cancer could promote proliferation and growth of cancer cells through directly targeting the tumor-suppressor EGR2, whose activation induces apoptosis (Wu et al., 2010b).

RUNX3 is an important tumor suppressor that is inactivated in many cancer types. miR$130 \mathrm{~b}$ expression was significantly higher in gastric tumors, and overexpression of miR-130b has also been reported to suppress TGF $\beta$-mediated Bim expression and apoptosis by targeting RUNX3 in gastric cancer cells (Lai et al., 2010). miR-375 was greatly downregulated in gastric cancer tissues, and its ectopic expression in gastric carcinoma cells reduced cell viability via the caspase dependent apoptosis pathway. miR-375 suppresses the Akt phosphorylation pathway through direct targeting of PDK1, a kinase that phosphorylates Akt. In addition to PDK1, miR-375 also targets 14-3-3zeta, a potent antiapoptotic gene, indicating that miR-375 is a candidate tumor suppressor miRNA in gastric carcinoma (Tsukamoto et al., 2010).

Chen et al. previously found that miRNA-200c could not only induce the expression of Ecadherin, but also increase the sensitivity of gastric cancer cells to cisplatin. miRNA-200c can indirectly regulate apoptosis through E-cadherin in gastric cancer cells, which may be a possible mechanism of miRNA-200c in inhibiting proliferation (Chen et al., 2010). SOX2 plays important roles in growth inhibition through cell cycle arrest and apoptosis, and that SOX2 expression is downregulated in gastric cancers. Otsubo et al. revealed that miR-126 inhibited SOX2 expression by targeting two binding sites in the 3'-untranslated region (3'UTR) of SOX2 mRNA. In addition, the authors found that expression of the placenta-specific 1 (PLAC1) gene was significantly downregulated by SOX2. These results indicate that miR126 is a novel miRNA that targets SOX2, and PLAC1 may be a novel downstream target gene of SOX2 in gastric cancer cells (Otsubo et al., 2011). Hou et al. showed decreased expression of miR-146a in gastric cancer and low expression of miR-146a was correlated with increased tumor size and poor differentiation. Overall survival time of patients with high miR-146a expression was significantly longer than that of patients with low expression of miR-146a. Overexpression of miR-146a inhibited cell proliferation and induced apoptosis in gastric cancer cells. miR-146a has potential as a novel suppressor gene in gastric cancer (Hou et al., 2011).

\section{3 miRNAs and proliferation}


miR-27a is upregulated in human gastric adenocarcinoma and was identified as an oncogenic miRNA in a gastric cancer cell line, in which it targets the tumor suppressor prohibitin, an evolutionary conserved and ubiquitous protein interacting with $\mathrm{pRb}$ and its family members. Downregulation of prohibitin by miR-27a may explain why suppression of miR-27a can inhibit gastric cancer cell growth (Liu et al., 2009). In p53-mutant human gastric cancer cells, overexpression of miR-34 increases caspase-3 activation and impairs the tumorsphere formation and growth, accumulating the cells in G1 phase. Restoration of miR34 expression resulted in a downregulation of Bcl-2, Notch1 and HMGA2, indicating that miR-34 may be involved in gastric cancer stem cell self-renewal/differentiation pathways (Ji et al., 2008). The expression of oncogene macrophage migration inhibitory factor (MIF) has been shown to be targeted by miR-451, whose expression is downregulated in gastric cancer. Bandres and colleagues show that the restoration of miR-451 in gastric cancer cells led to downregulation of the MIF gene, which is accompanied by reduction in cell proliferation and increased sensitivity to radiotherapy. In addition, a significant inverse correlation was found between miR-451 and MIF expression in gastric cancer biopsies (Bandres et al., 2009). Human miR-141, a member of the miR-200 family, has been reported to be associated with various tumorigenesis processes. Du et al. found that miR-141 was expressed at significantly low levels in primary gastric cancer, and overexpression of miR141 could inhibit the proliferation of gastric cancer cell lines. These results suggest that miR141 may be involved in the development of gastric cancer through its inhibitory effect on cell proliferation (Du et al., 2009).

miR-9 was downregulated in gastric cancer and targeted NF- $\mathrm{B} 1$ and thereby suppressing NF- $\kappa \mathrm{B}$ transcriptional activity. Restoration of miR-9 expression suppressed the proliferation of gastric cancer cells. NF-kB has been shown to be directly targeted by miRNA in gastric cancer. Aberrant activation of NF- $\mathrm{KB}$ signaling as a result of miRNA dysregulation may be an important molecular event in gastric tumorigenesis (Wan et al., 2010). Besides PDK1 and 14-3-3zeta, forced expression of miR-375 in gastric cancer cells significantly reduced the protein level of Janus kinase 2 (JAK2), indicating that JAK2 may be a miR-375 target gene. Moreover, ectopic expression of JAK2 can partially reverse the inhibition of cell proliferation caused by miR-375 and a significant inverse correlation between miR-375 expression and JAK2 protein level in gastric cancer (Ding et al., 2010).

Zhang et al. show that miR-650 is involved in lymphatic and distant metastasis in human gastric cancer. Ectopic expression of miR-650 promotes tumorigenesis and proliferation of gastric cancer cells through directly targeting the Inhibitor of Growth 4 (ING4) protein (Zhang et al., 2010). Ectopic expression of miR-29s significantly reduced the expression of Cdc42 and its downstream molecular PAK1 phosphorylation levels, and inhibited proliferation and migration in gastric cancer cells (Lang et al., 2010). miR-221 and miR-222 were discovered to induce cell growth and cell cycle progression via direct targeting of p27Kip1 in various human cancers. Upregulation of miR-221 and miR-222 induced the malignant phenotype of gastric cancer cells, in addition, knockdown of miR-221 and miR222 inhibited cell growth and invasion and increased the radiosensitivity of gastric cancer cells. These results demonstrate that miR-221 and miR-222 regulate radiosensitivity, and cell growth and invasion, possibly via direct modulation of PTEN expression (Chun-Zhi et al., 2010). Previous study showed that miR-23a was significantly upregulated in gastric adenocarcinoma tissues and miR-23a has been found to function as a growth-promoting factor in gastric cancer cells. Zhu et al. identified IL6R as a direct target gene for miR-23a 
and demonstrated that miR-23a can target IL6R and promote the growth activity of gastric adenocarcinoma cells in vitro (Zhu et al., 2010a). Song et al. found that miR-199a is highly expressed in gastric cancer tissues. miR-199a positively regulated gastric cancer cell proliferation through directly targeting the mitogen-activated protein kinase kinase kinase 11. The level of miR-199a expression in gastric cancer significantly correlated with clinical progression (Song et al., 2010). Expression of miR-203 was not significant in gastric cancer tissues compared to non-tumor counterparts, but miR-203 was correlated with tumor size, macroscopic type, and pT stage and miR-203 can inhibit the cell proliferation in gastric cancer cells. miR-203 may be associated with the proliferation of gastric cancers (Chiang et al., 2011).

Ectopic miR-16 or miR-21 expression has exhibited an effect on cell proliferation, and is mediated via EP2/4 receptors (Shin et al., 2011). MicroRNA microarray analyses revealed that miR-192 and -215 were significantly more upregulated in gastric carcinomas than in non-neoplastic stomach. In addition, expression levels of ALCAM were significantly lower in gastric cancers. Western blotting and luciferase assays were performed to confirm direct activated leukocyte cell adhesion molecule (ALCAM) targeting by miR-192 and -215 . Both miR-192 and -215 are overexpressed in vivo and exert cell growth -promoting effects in vitro (Jin et al., 2010). Previous studies have revealed that miR-148a and miR-152 are significantly downregulated in gastrointestinal cancers. The purpose of this study was to elucidate the molecular mechanisms by which miR-148b acts as a tumor suppressor in gastric cancer. Song et al. showed significant downregulation of miR-148b in gastric cancer tissues and four gastric cancer cell lines. The authors also found that miR-148b could inhibit cell proliferation in vitro and suppress tumorigenicity in vivo. CCKBR was identified as a target of miR-148b in cells, and inverse correlation was observed between the expression of CCKBR protein and miR-148b in gastric cancer tissues. These findings indicated that miR-148b targets CCKBR and is significant in suppressing gastric cancer cell growth (Song et al., 2011). Ectopic expression of CDX2, a caudal-related homeobox protein, is known to be associated with the development of gastric tumorigenesis. The inverse correlation between the miR-9 and CDX2 protein levels was demonstrated in gastric cancer cell lines. Inhibition of miR-9 significantly inhibited cell growth by promoting G1 cell cycle arrest in gastric cancer cells. Therefore, miR-9 might directly repress CDX2 expression resulting in the promotion of cell proliferation in gastric cancers (Rotkrua et al., 2011).

\section{4 miRNA and metastasis}

Migration and invasion are essential aspects of cancer cells metastasis. The high mobility group A2 (HMGA2) overexpression is a hallmark of gastric cancer. Motoyama and colleagues demonstrated that HMGA2 is negatively regulated by the let-7 miRNA family in gastric cancer cell lines. There is an inverse relationship between the expression of let-7 and HMGA2 in gastric cancer cell lines and primary gastric cancer tissues. High expression of HMGA2 in gastric cancer correlates with tumor invasion and is an independent prognostic factor (Motoyama et al., 2008). Zhang et al. also demonstrated that knockdown of miR-21 significantly decreased cell invasion and migration of gastric cancer cells (Zhang et al., 2008). miR-27a was found correlated between the tumor size and lymph node metastasis and may be associated with the prognosis in undifferentiated gastric cancer patients (Katada et al., 2009b). Downregulation of miR-218 is also implicated in metastatic gastric cancer. Robo1, one of several Slit receptors, is negatively regulated by miR-218. It has been shown 
that reduced expression of miR-218 in gastric cancer results in upregulation of its target Robo1, one of several Slit receptors, enhancing Slit/Robo1 signaling. Tie et al. demonstrated that restoration of miR-218 expression inhibits invasion and metastasis of gastric cancer cells in vitro and in vivo (Tie et al., 2010). Lang et al. found that ectopic expression of miRNA-29s inhibited migration in gastric cancer cells. Members of the miR-29 family can obviously inhibit migration and invasion of gastric cancer cells by targeting Cdc42 (Lang et al., 2010). The expression of let-7a was significantly lower in gastric carcinomas with lymph node metastasis than in those without metastasis (Zhu et al., 2010c). let-7 miRNAs generally play a tumor-suppressive role as shown in targeting oncogenes such as RAS and HMGA2 (Ohshima et al., 2010). The expression of miR-101 is downregulated in gastric cancer tissues and cells, and ectopic expression of miR-101 significantly inhibits cellular migration and invasion of gastric cancer cells. miR-101 may inversely regulate EZH2, Cox-2, Mcl-1 and Fos. These might indicate that miR-101 may function as a tumor suppressor in gastric cancer, as it has an inhibitory role in cellular proliferation and metastasis (Wang et al., 2010). Li et al. demonstrate that miR-107 is frequently upregulated in gastric cancers and its overexpression is significantly associated with gastric cancer metastasis. Furthermore, subsequent investigation characterized DRCE1 as a direct target of miR-107. These results suggested that miR-107 is an oncogene miRNA promoting gastric cancer metastasis through downregulation of DRCE1 (Li et al., 2010). miR-199a is highly expressed in metastatic gastric cancer tissues. MiR-199a positively regulated gastric cancer migration and invasion. Further studies showed that mitogen-activated protein kinase kinase kinase 11 was significantly downregulated by miR-199a and the level of miR-199a expression in gastric cancer significantly correlated with clinical progression (Song et al., 2010). Expression levels of both miR-192 and -215 were significantly higher in gastric cancer. miR-215 inhibits activated leukocyte cell adhesion molecule (ALCAM) expression at the posttranscriptional level. In addition, expression levels of ALCAM were significantly lower in gastric cancer. Overexpression of miR-192or -215 and ALCAM knockdown significantly increased the migration of gastric cancer cells (Jin et al., 2010). Takei et al. defined miR-516a-3p involved in cancer metastasis as a candidate anti-metastatic miRNA. Sulfatase1 is known to remove 6O-sulfates from heparan sulfate proteoglycans on the cell surface, causing release of membrane-bound Wnt ligands from cells. The authors documented that Sulfatase1 as a direct target of miR-516a-3p (Takei et al., 2011). Feng et al. identified miR-107 as a regulator of CDK6 expression. Expression of miR-107 in gastric cancer cell lines was found inversely correlated with CDK6 expression. Ectopic expression of miR-107 reduced expression of CDK6 and blocked invasion in the gastric cancer cells (Feng et al., 2011)..

\subsection{Multidrug resistance (MDR)}

$\mathrm{Xia}$ and colleagues demonstrated significant correlations between miRNA expression patterns and multidrug resistance, suggesting that miRNAs may play a role in chemoresistance. Up- or downregulation of several miRNAs can lead to modified sensitivity to anticancer treatments. miR-15b and miR-16 were downregulated in a multidrug resistant gastric cancer cell line. Enforced overexpression of miR-15b or miR-16 caused a significant increase of apoptosis after vincristine (VCR) therapy. The chemotherapy-sensitizing effect of miR-15b and miR-16 were mediated by modulation of apoptosis via targeting BCL2 (Xia et al., 2008). Zhu et al. investigated the role of miR-181b in the development of multidrug resistance in human the gastric cancer cell line. miR-181b was downregulated in the multidrug resistant human gastric cancer cell line. Enforced miR-181b expression reduced 
BCL2 protein level and sensitized gastric cancer cells to VCR-induced and cisplatin (CDDP)induced apoptosis. These findings suggest that miR-181b could play a role in the development of MDR in gastric cancer cells by targeting BCL2 (Zhu et al., 2010b).

\section{5. miRNAs as biomarkers in gastric cancer}

Most patients have advanced gastric cancer at diagnosis, resulting in a high frequency cause of death. The survival and prognosis of gastric cancer patients depends on stage of gastric cancer (Fujita, 2009). Unfortunately, highly sensitive and specific biomarkers for diagnosis and detection of gastric cancer in early stages are lacking. Therefore, it is essential to identify molecular biomarkers for early diagnosis and effective monitoring of the progression of gastric cancer, as well as for prospective development of therapeutic pharmacological reagents. miRNA is a putative candidate to improve diagnostic sensitivity of tumor markers for early stage tumors is beneficial for improving the survival rate of gastric cancer patients. Accumulating studies have shown the diagnostic and prognostic values of miRNAs in gastric cancer. In our study, clinicopathological analysis indicated that low expression of miR-34b and miR-129 is associated with a poor clinical prognosis feature (Tsai et al., 2011). Ueda et al. reported that low expression of let-7g and miR-433 and high expression of miR214 were associated with poor outcome (Ueda et al., 2010). Katada et al. indicated that miR$20 \mathrm{~b}$ or 150 overexpression in undifferentiated gastric cancer, and high level expression is associated with poor survival in patients (Katada et al., 2009a). A recent study analyzed the miRNA expression profile in 65 gastric cancer patients, 29 patients with recurrence and 36 patients without recurrence. Their results indicated that the combination of miR-375 and miR-142 could predict recurrence risk for GC patients (Zhang et al., 2011).

Recent studies have shown that quantities of circulating miRNAs exist in body fluids, including blood, and these miRNAs are derived generally from cell debris or transporting exosomes (Chen et al., 2008; Gilad et al., 2008). Chim et al. and Gilad et al. both demonstrate that the high abundance of placental miRNA in serum could reflect pregnancy conditions in maternal blood (Chim et al., 2008; Gilad et al., 2008). Mitchell et al. demonstrated that circulating miRNAs in serum are released from solid tumor, which could serve as a means for cancer detection (Mitchell et al., 2008). This cumulative evidence indicated that circulating miRNAs in blood might show promise as useful non-invasive biomarkers for diagnosis of gastric cancers. Liu et al. (Liu et al., 2011) identified a profile of five serum miRNAs (miR-1, miR-20a, miR-27a, miR-34 and miR-423-5p) as a biomarker for GC detection and their expression level was well correlated to tumor stage. In large-scale analysis, the plasma concentrations of miRNAs (miR-17-5p, miR-21, miR-106a, miR-106b) were significantly higher in GC patients, and significantly decreased in pre-operative serum compared with post-operative serum (Tsukamoto et al., 2010). Concluding above result, circulating miRNAs have a good potential to be novel biomarkers for the detection of gastric cancer and monitoring recurrence.

\section{Conclusion}

miRNAs represent a recently identified class of small, noncoding RNA molecules which control gene expression at post-transcriptional levels. In the past decade, there is a lot of evidence on the critical role of deregulated miRNAs in the pathogenesis and progression of human tumors, dysregulation of miRNA occurs in gastric cancer as well as other malignant 
diseases. The mechanisms by which miRNA takes part in tumor promotion and progression are various and complex. Most of researchers focus on common signaling mechanisms that control cell proliferation, apoptosis and metastasis. The association of miRNA deregulation explains great potential of utilizing miRNAs as targets for therapeutic intervention.

Gene profiling studies have demonstrated a number of significantly deregulated miRNAs and identified signatures of both diagnostic and prognostic value in gastric cancer. It has been shown that alterations in miRNA expression profiles can be used to estimate and monitor the success of potential therapeutic modalities. miRNAs play a role in the complicated gene regulation networks, and regulate the expression of multiple genes. Using miRNAs in combination with existing therapeutic strategies may synergistically affect the results of cancer treatment and improve survival of patients. Therefore, additional studies have to be carried out in future to verify the safety and efficiency of such treatment combinations in clinical therapies.

\section{References}

Bandres, E., N. Bitarte, F. Arias, J. Agorreta, P. Fortes, X. Agirre, R. Zarate, J. A. DiazGonzalez, N. Ramirez, J. J. Sola, P. Jimenez, J. Rodriguez \& J. Garcia-Foncillas (2009) microRNA-451 regulates macrophage migration inhibitory factor production and proliferation of gastrointestinal cancer cells. Clinical cancer research : an official journal of the American Association for Cancer Research, Vol.15, pp. 2281-90, ISSN 10780432

Bartel, D. P. (2004) MicroRNAs: genomics, biogenesis, mechanism, and function. Cell, Vol.116, 281-97.

Chen, Q., X. Chen, M. Zhang, Q. Fan, S. Luo \& X. Cao (2011) miR-137 Is Frequently DownRegulated in Gastric Cancer and Is a Negative Regulator of Cdc42. Dig Dis Sci. Vol.116, pp. 281-97, ISSN 0092-8674

Chen, X., Y. Ba, L. Ma, X. Cai, Y. Yin, K. Wang, J. Guo, Y. Zhang, J. Chen, X. Guo, Q. Li, X. Li, W. Wang, Y. Zhang, J. Wang, X. Jiang, Y. Xiang, C. Xu, P. Zheng, J. Zhang, R. Li, H. Zhang, X. Shang, T. Gong, G. Ning, J. Wang, K. Zen, J. Zhang \& C. Y. Zhang (2008) Characterization of microRNAs in serum: a novel class of biomarkers for diagnosis of cancer and other diseases. Cell Res, Vol.18, pp. 997-1006, ISSN 1748-7838

Chen, Y., J. Zuo, Y. Liu, H. Gao \& W. Liu (2010) Inhibitory effects of miRNA-200c on chemotherapy-resistance and cell proliferation of gastric cancer SGC7901/DDP cells. Chinese journal of cancer, Vol.29, pp. 1006-11, ISSN 1944-446X

Cheung, H. H., A. J. Davis, T. L. Lee, A. L. Pang, S. Nagrani, O. M. Rennert \& W. Y. Chan (2011) Methylation of an intronic region regulates miR-199a in testicular tumor malignancy. Oncogene., Vol.15, pp. 63-70, ISSN 1476-5594

Chiang, Y., Y. Song, Z. Wang, Y. Chen, Z. Yue, H. Xu, C. Xing \& Z. Liu (2011) Aberrant expression of miR-203 and its clinical significance in gastric and colorectal cancers. Journal of gastrointestinal surgery : official journal of the Society for Surgery of the Alimentary Tract, Vol.15, pp. 63-70, ISSN

Chim, S. S., T. K. Shing, E. C. Hung, T. Y. Leung, T. K. Lau, R. W. Chiu \& Y. M. Lo (2008) Detection and characterization of placental microRNAs in maternal plasma. Clin Chem, Vol.54, pp. 482-90, ISSN 0009-9147

Cho, W. J., J. M. Shin, J. S. Kim, M. R. Lee, K. S. Hong, J. H. Lee, K. H. Koo, J. W. Park \& K. S. Kim (2009) miR-372 regulates cell cycle and apoptosis of ags human gastric cancer 
cell line through direct regulation of LATS2. Mol Cells, Vol.28, pp. 521-7, ISSN 02191032

Chun-Zhi, Z., H. Lei, Z. An-Ling, F. Yan-Chao, Y. Xiao, W. Guang-Xiu, J. Zhi-Fan, P. Pei-Yu, Z. Qing-Yu \& K. Chun-Sheng (2010) MicroRNA-221 and microRNA-222 regulate gastric carcinoma cell proliferation and radioresistance by targeting PTEN. BMC Cancer, Vol.10, pp. 367, ISSN

Ding, L., Y. Xu, W. Zhang, Y. Deng, M. Si, Y. Du, H. Yao, X. Liu, Y. Ke, J. Si \& T. Zhou (2010) MiR-375 frequently downregulated in gastric cancer inhibits cell proliferation by targeting JAK2. Cell Res, Vol.20, pp. 784-93, ISSN 1748-7838

Du, Y., Y. Xu, L. Ding, H. Yao, H. Yu, T. Zhou \& J. Si (2009) Down-regulation of miR-141 in gastric cancer and its involvement in cell growth. J Gastroenterol, Vol.44, pp. 556-61, ISSN 0944-1174

Feng, L., Y. Xie, H. Zhang \& Y. Wu (2011) miR-107 targets cyclin-dependent kinase 6 expression, induces cell cycle G1 arrest and inhibits invasion in gastric cancer cells. Med Oncol. ISSN 1559-131X

Feng, R., X. Chen, Y. Yu, L. Su, B. Yu, J. Li, Q. Cai, M. Yan, B. Liu \& Z. Zhu (2010) miR-126 functions as a tumour suppressor in human gastric cancer. Cancer Lett, Vol.298, pp. 50-63, ISSN 1872-7980

Fujita, T. (2009) Gastric cancer. Lancet, Vol.374, pp. 1593-4; author reply pp. 1594-5, ISSN 1474-547X

Gao, C., Z. Zhang, W. Liu, S. Xiao, W. Gu \& H. Lu (2010) Reduced microRNA-218 expression is associated with high nuclear factor kappa B activation in gastric cancer. Cancer, Vol.116, pp. 41-9, ISSN 0008-543X

Gilad, S., E. Meiri, Y. Yogev, S. Benjamin, D. Lebanony, N. Yerushalmi, H. Benjamin, M. Kushnir, H. Cholakh, N. Melamed, Z. Bentwich, M. Hod, Y. Goren \& A. Chajut (2008) Serum microRNAs are promising novel biomarkers. PLoS One, Vol.3, pp. e3148, ISSN 1932-6203

Guo, J., Y. Miao, B. Xiao, R. Huan, Z. Jiang, D. Meng \& Y. Wang (2009) Differential expression of microRNA species in human gastric cancer versus non-tumorous tissues. J Gastroenterol Hepatol, Vol.24, pp. 652-7, ISSN 1440-1746

Guo, X., L. Guo, J. Ji, J. Zhang, J. Zhang, X. Chen, Q. Cai, J. Li, Q. Gu, B. Liu, Z. Zhu \& Y. Yu (2010) miRNA-331-3p directly targets E2F1 and induces growth arrest in human gastric cancer. Biochem Biophys Res Commun, Vol.398, pp. 1-6, ISSN 1090-2104

Guo, X., C. Jing, L. Li, L. Zhang, Y. Shi, J. Wang, J. Liu \& C. Li (2011) Down-regulation of VEZT gene expression in human gastric cancer involves promoter methylation and miR-43c. Biochem Biophys Res Commun, Vol.404, pp. 622-7, ISSN 1090-2104

Hashimoto, Y., Y. Akiyama, T. Otsubo, S. Shimada \& Y. Yuasa (2010) Involvement of epigenetically silenced microRNA-181c in gastric carcinogenesis. Carcinogenesis, Vol.31, pp. 777-84, ISSN 1460-2180

Hou, Z., L. Xie, L. Yu, X. Qian \& B. Liu (2011) MicroRNA-146a is down-regulated in gastric cancer and regulates cell proliferation and apoptosis. Med Oncol. ISSN 1559-131X

Ji, Q., X. Hao, Y. Meng, M. Zhang, J. Desano, D. Fan \& L. Xu (2008) Restoration of tumor suppressor miR-34 inhibits human p53-mutant gastric cancer tumorspheres. BMC Cancer, Vol.8, pp.266, ISSN 1471-2407 
Jiang, Z., J. Guo, B. Xiao, Y. Miao, R. Huang, D. Li \& Y. Zhang (2010) Increased expression of miR-421 in human gastric carcinoma and its clinical association. J Gastroenterol, Vol.45, pp. 17-23, ISSN 1435-5922

Jin, Z., F. M. Selaru, Y. Cheng, T. Kan, R. Agarwal, Y. Mori, A. V. Olaru, J. Yang, S. David, J. P. Hamilton, J. M. Abraham, J. Harmon, M. Duncan, E. A. Montgomery \& S. J. Meltzer (2010) MicroRNA-192 and -215 are upregulated in human gastric cancer in vivo and suppress ALCAM expression in vitro. Oncogene. Vol. pp. , ISSN 1476-5594

Katada, T., H. Ishiguro, Y. Kuwabara, M. Kimura, A. Mitui, Y. Mori, R. Ogawa, K. Harata \& Y. Fujii (2009) microRNA expression profile in undifferentiated gastric cancer. International journal of oncology, Vol.34, pp. 537-42, ISSN 1019-6439

Kim, J., S. Y. Min, H. E. Lee \& W. H. Kim (2011) Aberrant DNA methylation and tumor suppressive activity of the EBF3 gene in gastric carcinoma. International journal of cancer. Journal international du cancer, ISSN 1097-0215

Kim, M. S., J. E. Oh, Y. R. Kim, S. W. Park, M. R. Kang, S. S. Kim, C. H. Ahn, N. J. Yoo \& S. H. Lee (2010) Somatic mutations and losses of expression of microRNA regulationrelated genes AGO2 and TNRC6A in gastric and colorectal cancers. The Journal of pathology, Vol.221, pp. 139-46, ISSN 1096-9896

Kim, V. N. (2005) Small RNAs: classification, biogenesis, and function. Mol Cells, Vol.19, pp. 1-15, ISSN 1016-8478

Kim, Y. K., J. Yu, T. S. Han, S. Y. Park, B. Namkoong, D. H. Kim, K. Hur, M. W. Yoo, H. J. Lee, H. K. Yang \& V. N. Kim (2009) Functional links between clustered microRNAs: suppression of cell-cycle inhibitors by microRNA clusters in gastric cancer. Nucleic Acids Res, Vol.37, pp. 1672-81, ISSN 1362-4962

Lai, K. W., K. X. Koh, M. Loh, K. Tada, M. M. Subramaniam, X. Y. Lim, A. Vaithilingam, M. Salto-Tellez, B. Iacopetta, Y. Ito \& R. Soong (2010) MicroRNA-130b regulates the tumour suppressor RUNX3 in gastric cancer. Eur J Cancer, Vol.46, pp. 1456-63, ISSN 1879-0852

Lang, N., M. Liu, Q. L. Tang, X. Chen, Z. Liu \& F. Bi (2010) Effects of microRNA-29 family members on proliferation and invasion of gastric cancer cell lines. Chin J Cancer, Vol.29, pp. 603-10, ISSN 1944-446X

Li, X., Y. Zhang, Y. Shi, G. Dong, J. Liang, Y. Han, X. Wang, Q. Zhao, J. Ding, K. Wu \& D. Fan (2010) MicroRNA-107, an Oncogene MicroRNA that Regulates Tumor Invasion and Metastasis By Targeting DICER1 in Gastric Cancer: MiR-107 promotes gastric cancer invasion and metastasis. J Cell Mol Med. Vol. pp. , ISSN 1582-4934

Liu, R., C. Zhang, Z. Hu, G. Li, C. Wang, C. Yang, D. Huang, X. Chen, H. Zhang, R. Zhuang, T. Deng, H. Liu, J. Yin, S. Wang, K. Zen, Y. Ba \& C. Y. Zhang (2011) A fivemicroRNA signature identified from genome-wide serum microRNA expression profiling serves as a fingerprint for gastric cancer diagnosis. Eur J Cancer, Vol.47, pp. 784-91, ISSN 1879-0852

Liu, T., H. Tang, Y. Lang, M. Liu \& X. Li (2009) MicroRNA-27a functions as an oncogene in gastric adenocarcinoma by targeting prohibitin. Cancer Lett, Vol.273, pp. 233-42, ISSN 1872-7980

Luo, H., H. Zhang, Z. Zhang, X. Zhang, B. Ning, J. Guo, N. Nie, B. Liu \& X. Wu (2009) Down-regulated miR-9 and miR-433 in human gastric carcinoma. J Exp Clin Cancer Res, Vol.28, pp. 82, ISSN 1756-9966 
Mitchell, P. S., R. K. Parkin, E. M. Kroh, B. R. Fritz, S. K. Wyman, E. L. PogosovaAgadjanyan, A. Peterson, J. Noteboom, K. C. O'Briant, A. Allen, D. W. Lin, N. Urban, C. W. Drescher, B. S. Knudsen, D. L. Stirewalt, R. Gentleman, R. L. Vessella, P. S. Nelson, D. B. Martin \& M. Tewari (2008) Circulating microRNAs as stable blood-based markers for cancer detection. Proc Natl Acad Sci U S A, Vol.105, pp. 10513-8, ISSN 1091-6490

Motoyama, K., H. Inoue, K. Mimori, F. Tanaka, K. Kojima, H. Uetake, K. Sugihara \& M. Mori (2010) Clinicopathological and prognostic significance of PDCD4 and microRNA-21 in human gastric cancer. Int J Oncol, Vol.36, pp. 1089-95, ISSN 17912423

Motoyama, K., H. Inoue, Y. Nakamura, H. Uetake, K. Sugihara \& M. Mori (2008) Clinical significance of high mobility group A2 in human gastric cancer and its relationship to let-7 microRNA family. Clin Cancer Res, Vol.14, pp. 2334-40, ISSN 1078-0432

Nishida, N., K. Mimori, M. Fabbri, T. Yokobori, T. Sudo, F. Tanaka, K. Shibata, H. Ishii, Y. Doki \& M. Mori (2011) MicroRNA-125a-5p is an independent prognostic factor in gastric cancer,and inhibits the proliferation of human gastric cancer cells in combination with trastuzumab. Clin Cancer Res. ISSN 1078-0432

Noguer-Dance, M., S. Abu-Amero, M. Al-Khtib, A. Lefevre, P. Coullin, G. E. Moore \& J. Cavaille (2010) The primate-specific microRNA gene cluster (C19MC) is imprinted in the placenta. Hum Mol Genet, Vol.19, pp. 3566-82, ISSN 1460-2083

Ohshima, K., K. Inoue, A. Fujiwara, K. Hatakeyama, K. Kanto, Y. Watanabe, K. Muramatsu, Y. Fukuda, S. Ogura, K. Yamaguchi \& T. Mochizuki (2010) Let-7 microRNA family is selectively secreted into the extracellular environment via exosomes in a metastatic gastric cancer cell line. PLoS One, Vol.5, pp. e13247, ISSN 1932-6203

Otsubo, T., Y. Akiyama, Y. Hashimoto, S. Shimada, K. Goto \& Y. Yuasa (2011) MicroRNA126 Inhibits SOX2 Expression and Contributes to Gastric Carcinogenesis. PLoS One, Vol.6, pp. e16617, ISSN 1932-6203

Pan, J., H. Hu, Z. Zhou, L. Sun, L. Peng, L. Yu, J. Liu, Z. Yang \& Y. Ran (2010) Tumorsuppressive mir-663 gene induces mitotic catastrophe growth arrest in human gastric cancer cells. Oncology reports, Vol.24, pp. 105-12, ISSN 1791-2431

Parkin, D. M., P. Pisani \& J. Ferlay (1999) Global cancer statistics. CA: a cancer journal for clinicians, Vol.49, pp. 33-64, ISSN 0007-9235

Petrocca, F., R. Visone, M. R. Onelli, M. H. Shah, M. S. Nicoloso, I. de Martino, D. Iliopoulos, E. Pilozzi, C. G. Liu, M. Negrini, L. Cavazzini, S. Volinia, H. Alder, L. P. Ruco, G. Baldassarre, C. M. Croce \& A. Vecchione (2008) E2F1-regulated microRNAs impair TGFbeta-dependent cell-cycle arrest and apoptosis in gastric cancer. Cancer Cell, Vol.13, pp. 272-86, ISSN 1878-3686

Ribeiro-dos-Santos, A., A. S. Khayat, A. Silva, D. O. Alencar, J. Lobato, L. Luz, D. G. Pinheiro, L. Varuzza, M. Assumpcao, P. Assumpcao, S. Santos, D. L. Zanette, W. A. Silva, Jr., R. Burbano \& S. Darnet (2010) Ultra-deep sequencing reveals the microRNA expression pattern of the human stomach. PLoS One, Vol.5, pp. e13205, ISSN 1932-6203

Rotkrua, P., Y. Akiyama, Y. Hashimoto, T. Otsubo \& Y. Yuasa (2011) MiR-9 down-regulates CDX2 expression in gastric cancer cells. Int J Cancer. Vol. pp. , ISSN 1097-0215

Saito, Y., H. Suzuki, H. Tsugawa, I. Nakagawa, J. Matsuzaki, Y. Kanai \& T. Hibi (2009) Chromatin remodeling at Alu repeats by epigenetic treatment activates silenced 
microRNA-512-5p with downregulation of Mcl-1 in human gastric cancer cells. Oncogene, Vol.28, pp. 2738-44, ISSN 1476-5594

Shen, R., S. Pan, S. Qi, X. Lin \& S. Cheng (2010) Epigenetic repression of microRNA-129-2 leads to overexpression of SOX4 in gastric cancer. Biochem Biophys Res Commun, 394, pp. 1047-52, ISSN 1090-2104

Shin, V. Y., H. Jin, E. K. Ng, A. S. Cheng, W. W. Chong, C. Y. Wong, W. K. Leung, J. J. Sung \& K. M. Chu (2011) NF-kappaB targets miR-16 and miR-21 in gastric cancer: involvement of prostaglandin E receptors. Carcinogenesis, Vol.32, pp. 240-5, ISSN $1460-2180$

Shinozaki, A., T. Sakatani, T. Ushiku, R. Hino, M. Isogai, S. Ishikawa, H. Uozaki, K. Takada \& M. Fukayama (2010) Downregulation of microRNA-200 in EBV-associated gastric carcinoma. Cancer Res, Vol.70, pp. 4719-27, ISSN 1538-7445

Song, G., H. Zeng, J. Li, L. Xiao, Y. He, Y. Tang \& Y. Li (2010) miR-199a regulates the tumor suppressor mitogen-activated protein kinase kinase kinase 11 in gastric cancer. Biol Pharm Bull, Vol.33, pp. 1822-7, ISSN 1347-5215

Song, Y. X., Z. Y. Yue, Z. N. Wang, Y. Y. Xu, Y. Luo, H. M. Xu, X. Zhang, L. Jiang, C. Z. Xing \& Y. Zhang (2011) MicroRNA-148b is frequently down-regulated in gastric cancer and acts as a tumor suppressor by inhibiting cell proliferation. Mol Cancer, Vol.10, pp. 1, ISSN 1476-4598

Suzuki, H., E. Yamamoto, M. Nojima, M. Kai, H. O. Yamano, K. Yoshikawa, T. Kimura, T. Kudo, E. Harada, T. Sugai, H. Takamaru, T. Niinuma, R. Maruyama, H. Yamamoto, T. Tokino, K. Imai, M. Toyota \& Y. Shinomura (2010) Methylation-associated silencing of microRNA-34b/c in gastric cancer and its involvement in an epigenetic field defect. Carcinogenesis, Vol.31, pp. 2066-73, ISSN 1460-2180

Takei, Y., M. Takigahira, K. Mihara, Y. Tarumi \& K. Yanagihara (2011) The MetastasisAssociated microRNA miR-516a-3p Is a Novel Therapeutic Target for Inhibiting Peritoneal Dissemination of Human Scirrhous Gastric Cancer. Cancer Res, Vol.71, pp. 1442-1453, ISSN 1538-7445

Tchernitsa, O., A. Kasajima, R. Schafer, R. J. Kuban, U. Ungethum, B. Gyorffy, U. Neumann, E. Simon, W. Weichert, M. P. Ebert \& C. Rocken (2010) Systematic evaluation of the miRNA-ome and its downstream effects on mRNA expression identifies gastric cancer progression. The Journal of pathology, Vol.222, pp. 310-9, ISSN 1096-9896

Tie, J., Y. Pan, L. Zhao, K. Wu, J. Liu, S. Sun, X. Guo, B. Wang, Y. Gang, Y. Zhang, Q. Li, T. Qiao, Q. Zhao, Y. Nie \& D. Fan (2010) MiR-218 inhibits invasion and metastasis of gastric cancer by targeting the Robo1 receptor. PLoS Genet, Vol. 6, pp. e1000879, ISSN 1553-7404

Tsai, K. W., L. Y. Hu, C. W. Wu, S. C. Li, C. H. Lai, H. W. Kao, W. L. Fang \& W. C. Lin (2010) Epigenetic regulation of miR-196b expression in gastric cancer. Genes Chromosomes Cancer, Vol.49, pp. 969-80, ISSN 1098-2264

Tsai, K. W., H. W. Kao, H. C. Chen, S. J. Chen \& W. C. Lin (2009) Epigenetic control of the expression of a primate-specific microRNA cluster in human cancer cells. Epigenetics, 4, pp. 587-92, ISSN 1559-2308

Tsai, K. W., C. W. Wu, L. Y. Hu, S. C. Li, Y. L. Liao, C. H. Lai, H. W. Kao, W. L. Fang, K. H. Huang, W. C. Chan \& W. C. Lin (2011) Epigenetic regulation of miR-34b and miR129 expression in gastric cancer. Int J Cancer. ISSN 1097-0215 
Tsukamoto, Y., C. Nakada, T. Noguchi, M. Tanigawa, L. T. Nguyen, T. Uchida, N. Hijiya, K. Matsuura, T. Fujioka, M. Seto \& M. Moriyama (2010) MicroRNA-375 is downregulated in gastric carcinomas and regulates cell survival by targeting PDK1 and 14-3-3zeta. Cancer Res, Vol.70, pp. 2339-49, ISSN 1538-7445

Ueda, T., S. Volinia, H. Okumura, M. Shimizu, C. Taccioli, S. Rossi, H. Alder, C. G. Liu, N. Oue, W. Yasui, K. Yoshida, H. Sasaki, S. Nomura, Y. Seto, M. Kaminishi, G. A. Calin \& C. M. Croce (2010) Relation between microRNA expression and progression and prognosis of gastric cancer: a microRNA expression analysis. Lancet Oncol, Vol.11, pp. 136-46, ISSN 1474-5488

Varambally, S., Q. Cao, R. S. Mani, S. Shankar, X. Wang, B. Ateeq, B. Laxman, X. Cao, X. Jing, K. Ramnarayanan, J. C. Brenner, J. Yu, J. H. Kim, B. Han, P. Tan, C. KumarSinha, R. J. Lonigro, N. Palanisamy, C. A. Maher \& A. M. Chinnaiyan (2008) Genomic loss of microRNA-101 leads to overexpression of histone methyltransferase EZH2 in cancer. Science, Vol.322, pp. 1695-9, ISSN 1095-9203

Volinia, S., G. A. Calin, C. G. Liu, S. Ambs, A. Cimmino, F. Petrocca, R. Visone, M. Iorio, C. Roldo, M. Ferracin, R. L. Prueitt, N. Yanaihara, G. Lanza, A. Scarpa, A. Vecchione, M. Negrini, C. C. Harris \& C. M. Croce (2006) A microRNA expression signature of human solid tumors defines cancer gene targets. Proceedings of the National Academy of Sciences of the United States of America, Vol.103, pp. 2257-61, ISSN 0027-8424

Wada, R., Y. Akiyama, Y. Hashimoto, H. Fukamachi \& Y. Yuasa (2010) miR-212 is downregulated and suppresses methyl-CpG-binding protein MeCP2 in human gastric cancer. Int J Cancer, Vol.127, pp. 1106-14, ISSN 1097-0215

Wan, H. Y., L. M. Guo, T. Liu, M. Liu, X. Li \& H. Tang (2010) Regulation of the transcription factor NF-kappaB1 by microRNA-9 in human gastric adenocarcinoma. Mol Cancer, Vol.9, pp. 16, ISSN 1476-4598

Wang, H. J., H. J. Ruan, X. J. He, Y. Y. Ma, X. T. Jiang, Y. J. Xia, Z. Y. Ye \& H. Q. Tao (2010) MicroRNA-101 is down-regulated in gastric cancer and involved in cell migration and invasion. Eur J Cancer. ISSN 1879-0852

Wang, J., Q. Wang, H. Liu, B. Hu, W. Zhou \& Y. Cheng (2010) MicroRNA expression and its implication for the diagnosis and therapeutic strategies of gastric cancer. Cancer letters, Vol.297, pp.137-43, ISSN 1872-7980

Watanabe, Y. \& M. Maekawa (2010) Methylation of DNA in cancer. Adv Clin Chem, Vol.52, pp. 145-67, ISSN 0065-2423

Wu, J., J. Qian, C. Li, L. Kwok, F. Cheng, P. Liu, C. Perdomo, D. Kotton, C. Vaziri, C. Anderlind, A. Spira, W. V. Cardoso \& J. Lu (2010a) miR-129 regulates cell proliferation by downregulating Cdk6 expression. Cell Cycle, Vol.9, pp. 1809-18, ISSN 1551-4005

Wu, Q., H. Jin, Z. Yang, G. Luo, Y. Lu, K. Li, G. Ren, T. Su, Y. Pan, B. Feng, Z. Xue, X. Wang \& D. Fan (2010b) MiR-150 promotes gastric cancer proliferation by negatively regulating the pro-apoptotic gene EGR2. Biochem Biophys Res Commun, Vol.392, pp. 340-5, ISSN 1090-2104

Wu, W. K., C. W. Lee, C. H. Cho, D. Fan, K. Wu, J. Yu \& J. J. Sung (2010) MicroRNA dysregulation in gastric cancer: a new player enters the game. Oncogene, Vol.29, pp. 5761-71, ISSN 1476-5594 
Xia, L., D. Zhang, R. Du, Y. Pan, L. Zhao, S. Sun, L. Hong, J. Liu \& D. Fan (2008) miR-15b and miR-16 modulate multidrug resistance by targeting BCL2 in human gastric cancer cells. Int J Cancer, Vol.123, pp. 372-9, ISSN 1097-0215

Xu, L., F. Wang, X. F. Xu, W. H. Mo, Y. J. Xia, R. Wan, X. P. Wang \& C. Y. Guo (2010) Downregulation of miR-212 expression by DNA hypermethylation in human gastric cancer cells. Med Oncol. ISSN 1559-131X

Yang, Q., Z. Jie, H. Cao, A. R. Greenlee, C. Yang, F. Zou \& Y. Jiang (2011) Low-level expression of let-7a in gastric cancer and its involvement in tumorigenesis by targeting RAB40C. Carcinogenesis. ISSN 1460-2180

Zhang, X., Z. Yan, J. Zhang, L. Gong, W. Li, J. Cui, Y. Liu, Z. Gao, J. Li, L. Shen \& Y. Lu (2011) Combination of hsa-miR-375 and hsa-miR-142-5p as a predictor for recurrence risk in gastric cancer patients following surgical resection. Ann Oncol. ISSN 1569-8041

Zhang, X., W. Zhu, J. Zhang, S. Huo, L. Zhou, Z. Gu \& M. Zhang (2010) MicroRNA-650 targets ING4 to promote gastric cancer tumorigenicity. Biochem Biophys Res Commun, Vol.395, pp. 275-80, ISSN 1090-2104

Zhang, Z., Z. Li, C. Gao, P. Chen, J. Chen, W. Liu, S. Xiao \& H. Lu (2008) miR-21 plays a pivotal role in gastric cancer pathogenesis and progression. Laboratory investigation; a journal of technical methods and pathology, Vol.88, pp. 1358-66, ISSN 1530-0307

Zhu, L. H., T. Liu, H. Tang, R. Q. Tian, C. Su, M. Liu \& X. Li (2010a) MicroRNA-23a promotes the growth of gastric adenocarcinoma cell line MGC803 and downregulates interleukin-6 receptor. The FEBS journal, Vol.277, pp. 3726-34, ISSN $1742-4658$

Zhu, W., X. Shan, T. Wang, Y. Shu \& P. Liu (2010b) miR-181b modulates multidrug resistance by targeting BCL2 in human cancer cell lines. Int J Cancer, Vol.127, pp. 2520-9, ISSN 1097-0215

Zhu, W., D. Zhu, S. Lu, T. Wang, J. Wang, B. Jiang, Y. Shu \& P. Liu (2011) miR-497 modulates multidrug resistance of human cancer cell lines by targeting BCL2. Med Oncol. Vol. pp, ISSN 1559-131X

Zhu, Y. M., Z. X. Zhong \& Z. M. Liu (2010c) Relationship between let-7a and gastric mucosa cancerization and its significance. World journal of gastroenterology : WJG, Vol.16, pp. 3325-9, ISSN 1007-9327 


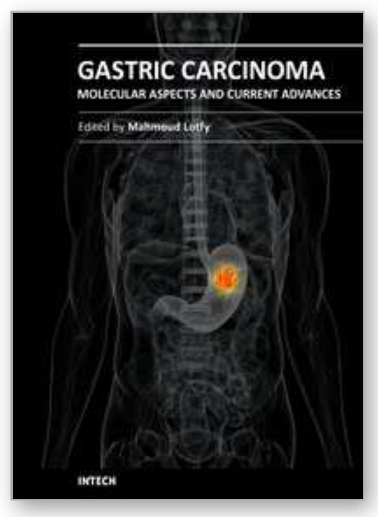

\section{Gastric Carcinoma - Molecular Aspects and Current Advances}

Edited by Prof. Mahmoud Lotfy

ISBN 978-953-307-412-2

Hard cover, 354 pages

Publisher InTech

Published online 15, June, 2011

Published in print edition June, 2011

Gastric cancer is one of the most common tumors worldwide. It has a heterogeneous milieu, where the genetic background, tumor immunology, oxidative stress, and microbial infections are key players in the multiple stages of tumorigenesis. These diverse factors are linked to the prognosis of the gastric cancer and the survival of gastric cancer patients. This book is appropriate for scientists and students in the field of oncology, gastroenterology, molecular biology, immunology, cell biology, biology, biochemistry, and pathology. This authoritative text carefully explains the fundamentals, providing a general overview of the principles followed by more detailed explanations of these recent topics efficiently. The topics presented herein contain the most recent knowledge in gastric cancer concerning the oncogenic signaling, genetic instability, the epigenetic aspect, molecular features and their clinical implications, miRNAs, integrin and E-cadherin, carbohydrateassociated-transferases, free radicals, immune cell responses, mucins, Helicobacter-pylori, neoadjuvant and adjuvant therapy, prophylactic strategy for peritoneal recurrence, and hepatic metastasis.

\section{How to reference}

In order to correctly reference this scholarly work, feel free to copy and paste the following:

Yu-Lun Liao, Kuo-Wang Tsai and Wen-Chang Lin (2011). miRNAs in Gastric Cancer, Gastric Carcinoma Molecular Aspects and Current Advances, Prof. Mahmoud Lotfy (Ed.), ISBN: 978-953-307-412-2, InTech, Available from: http://www.intechopen.com/books/gastric-carcinoma-molecular-aspects-and-currentadvances/mirnas-in-gastric-cancer

\section{INTECH}

open science | open minds

\section{InTech Europe}

University Campus STeP Ri

Slavka Krautzeka 83/A

51000 Rijeka, Croatia

Phone: +385 (51) 770447

Fax: +385 (51) 686166

www.intechopen.com

\section{InTech China}

Unit 405, Office Block, Hotel Equatorial Shanghai

No.65, Yan An Road (West), Shanghai, 200040, China

中国上海市延安西路65号上海国际贵都大饭店办公楼405单元

Phone: +86-21-62489820

Fax: $+86-21-62489821$ 
(C) 2011 The Author(s). Licensee IntechOpen. This chapter is distributed under the terms of the Creative Commons Attribution-NonCommercialShareAlike-3.0 License, which permits use, distribution and reproduction for non-commercial purposes, provided the original is properly cited and derivative works building on this content are distributed under the same license. 